\title{
Tempo de gestação de éguas Puro Sangue Inglês mantidas em clima tropical e subtropical
}

Gabriela Castro da Silva ${ }^{[a]}$, Bruna da Rosa Curcio ${ }^{[b]}$, Carlos Eduardo Wayne Nogueira ${ }^{[b]}$, Cláudia Haetinger ${ }^{[b]}$, Fabio Lima ${ }^{[b]}$, Fernanda Maria Pazinato ${ }^{[b]}$, Bruna dos Santos Suñe Moraes ${ }^{[b]}$, Natane Miranda Saraiva $a^{[b]}$, Igor Canisso $0^{[c]}$

\footnotetext{
[a] Associação Brasileira de Médicos Veterinários de Equídeos (ABRAVEQ), Pelotas, RS, Brasil

[b] Universidade Federal de Pelotas (UFPel), Pelotas, RS, Brasil

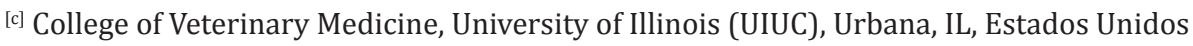

*Autor correspondente

e-mail: gabicastrovini@gmail.com

\section{Resumo}

O tempo de gestação em éguas Puro Sangue Inglês (PSI) é muito variável. Fatores ambientais (luminosidade, temperatura, umidade, nutrição) são conhecidos por terem grande influência na reprodução, já descrita em espécies domésticas. Em equinos, a luminosidade e a nutrição são bem caracterizados por controlar a ciclicidade reprodutiva e a duração da gestação. Entretanto, informações dos efeitos de temperatura, precipitação e umidade ainda são limitadas. Desta forma, hipotetizamos que a combinação da temperatura e umidade no mês do parto afetam a duração do tempo gestacional em éguas mantidas em clima tropical e subtropical. 0 objetivo deste estudo foi avaliar os efeitos de temperatura e umidade no mês do parto no tempo gestacional em éguas PSI. Foi avaliado o tempo gestacional de 376 éguas PSI nas regiões Sul e Sudeste do Brasil, com gestações normais e potros saudáveis ao nascimento. A partir destes animais foram coletados os dados: idade da égua (jovens de 3-7 e maduras >8 anos), número de partos (primíparas ou multíparas) e o gênero do potro. As matrizes eram provenientes de três criatórios: criatório 1, na região de Bagé/RS (clima subtropical, $n=400$ gestações de 203 éguas); criatório 2, na região de São José dos Pinhais/PR (clima subtropical, $n=98$ gestações de 49 éguas); e criatório 3, na região de Rio Claro/SP (clima tropical, $n=202$ gestações de 124 éguas). Todas as éguas foram submetidas à condição de manejo e nutrição semelhantes, mantidas em pastagem durante o dia, suplementadas com grãos e alojadas em estábulos à noite. As variáveis climatológicas utilizadas incluíram temperatura de bulbo seco (Tdb), umidade relativa (UR), precipitação e índice de temperatura e umidade calculado (ITU). Os dados meteriológicos foram obtidos no serviço nacional de meteorologia, nas estações climáticas referentes à região de cada um dos três criatórios. Todas as éguas foram cobertas por monta natural, e a ovulação confirmada através de palpação 
transretal e ultrassonografia. Os dados paramétricos foram avaliados através de ANOVA e a comparação das médias realizada por teste de Tukey. Foram considerados a interação do local com o gênero do potro e idade das éguas. Foi considerado valor significativo $\mathrm{P}<0,05$ para o teste de normalidade de Shapiro-Wilks, e os resultados expressos em médias e pelo desvio padrão ( \pm DP) e intervalo mínimo-máximo. Potros machos (343 $\pm 10 ; 320-390 \mathrm{~d} ; \mathrm{n}=361$ ) tiveram gestação mais longa que as fêmeas ( $340 \pm 12 ; 321-375 \mathrm{~d} ; \mathrm{n}=359$ ) ( $p=0,03$ ), sem efeitos significativos da localização ou interações com as condições climáticas. As éguas maduras ( $344 \pm 11 ; 321$-390 d; $\mathrm{n}=342$ gestações) tiveram maior tempo de gestação do que as éguas jovens (341 $\pm 11 ; 320$-375 d; $\mathrm{n}=378$ gestações) ( $\mathrm{p}=0,009$ ). 0 criatório 1 apresentou maior tempo de gestação (344 $\pm 12,320$-390d) do que os criatórios 2 (338 $\pm 7 ; 321-358$ d) e $3(337 \pm 7 ; 320-366$ d) $(\mathrm{P}<0,001)$. Umidade relativa e precipitação foram similares ( $\mathrm{P}>0.05)$ para o criatório $1\left(73 \pm 7 \% ; 140 \pm 99 \mathrm{~mm}^{3}\right)$ e 2 $\left(80 \pm 5 \%\right.$; $\left.140 \pm 91 \mathrm{~mm}^{3}\right)$; ambos os parâmetros foram superiores $(\mathrm{P}<0.001)$ no criatório $3(67 \pm 3 \%$; 40 $\pm 46 \mathrm{~mm}^{3}$. A Tdb e ITU são significativamente diferentes ( $\left.\mathrm{P}<0.001\right)$ para todos os três criatórios: 1 (15.4 \pm 2.9 oC; $60 \pm 4.5), 2(17.3 \pm 60 \mathrm{C} ; 64.4 \pm 9.6)$ e $3(20 \pm 2$ oC; $66.3 \pm 3)$. Não houve interações significativas $(P>0,05)$ entre localização, gênero do potro, número de partos e idade da égua em relação ao tempo de gestação, sendo que não foi observada diferença na média de idade das éguas entre os três criatórios. Uma vez que as éguas foram manejadas de forma similar, os efeitos observados na duração da gestação podem ser atribuídos à temperatura e, consequentemente, ao ITU, ao invés da localização; do mesmo modo, umidade e precipitação não parecem ter afetado a duração da gestação. Assim, conclui-se que éguas que permanecem em temperatura mais baixas no mês do parto apresentam maiores tempo de gestação. Contudo, mais estudos são necessários para estabelecer as médias de temperatura e ITU que podem influenciar na gestação.

Palavras-chave: Reprodução. Gestação. Temperatura. 